\title{
30. Bipolarity, Multipolarity, and the Future
}

Richard N. Rosecrance is Professor of Political Science at the University of California, Berkeley. A leading student of international systems and the dynamics that sustain and transform them, he has authored Action and Reaction in World Politics (1963) and Defense of the Realm: British Strategy in the Nuclear Epach (1967), as well as edited The Dispersion of Nuclear Weapons (1966). In this selection Professor Rosecrance traces a structure of the global international system that falls midway between the contrasting structures identified in the two previous selections. His invigorating analysis should press the reader to reassess again the prevailing structure and stability of world politics in the nuclear age. [Reprinted from The Journal of Conflict Resolution, $X$ (I966) 3I4-27, by permission of the author and the publisher. Copyright 1966 by the University of Michigan.]

In April 1961 Dr. Stanley Hoffmann of Harvard University reminded us that it was no longer sufficient to design ideal schemes for the preservation of peace on earth (Hoffmann, 196r). World government might be completely desirable, but it was also unattainable. In the future our projected utopias should also be "relevant." Various writers have since taken up Hoffmann's challenge, and we are now told that "bipolarity" on the one hand or "multipolarity" on the other are practical answers to major current difficulties (see Waltz, 1964; Deutsch and Singer, 1964). The purpose of the present essay is to examine these proposed "relevant utopias" and to offer an alternative view. In the end we will discover that neither bipolarity nor multipolarity provides general solutions to basic conflicts in the contemporary international system.

\section{Bipolarity}

The argument for bipolarity is dual: it is allegedly desirable, as opposed, say, to a multipolar inter- national order; it is also a continuing state of affairs. Four reasons are given to persuade us that a bipolar order will reduce international violence. First, "with only two world powers there are no peripheries" (Waltz, 1964, p. 882). This juxtaposition entails a vital interest and involvement in all the outcomes of world politics. Both the Soviets and the Americans must be concerned with happenings in widely separated areas of the globe-Korea, Cuba, Vietnam, Eastern Europe, to name but a few. Far from leading to violence, however, the commitment on opposite sides has led to a solid and determinate balance. No expansion could be decisively successful; counterpressure is always applied. The very existence of serial confrontation renders the balance more stable. Each counterposition of power discourages the next. There are no realms open to aggrandizement.

Second, not only is the competition extensive, but its intensity has increased. The space race, economic growth, military preparedness, the propaganda struggle, and domestic issues of all sorts 
have assumed significance in international relations. "Policy proceeds by imitation, with occasional attempts to outflank" (Waltz, I964, p. 883). Nothing escapes calculation in terms of the international balance. By asserting the interests of the two great powers in even minor equilibrations of the balance, the bipolar international system keeps on an even keel; nice adjustments do not pass unnoticed. A third stabilizing factor is the "nearly constant presence of pressure and the recurrence of crises" (Waltz, I964, p. 883). Crises are natural and even desirable in a condition of conflict. If crises do not occur, it means that one side or the other is neglecting its own interests. Maintenance of the balance will then require small or large wars waged later on. As long as there are only two major protagonists, there can be no question of the impact caused by a favorable change in the position of one; there also, presumably, can be no uncertainty of an "equal and opposite reaction." "When possible enemies are several in number [however] unity of action among states is difficult to secure." Under bipolar conditions, moreover, "caution, moderation, and the management of crisis come to be of great . . importance" (Waltz, I964, p. 884). One pushes to the limit, but not beyond.

Fourth, and finally, the preponderant power of the two superstates means that minor shifts in the balance are not of decisive significance. The U.S. "lost" China in 1949, the Soviet Union "lost" it in 1962, but neither change drastically altered the Russian-American equipoise. The two states were so strong they could accommodate change. While defection of a major Western European state would be significant, "a five per cent growth rate sustained for three years would add to the American gross national product an amount greater than the entire gross national product of Britain or France or West Germany" (Waltz, I964, p. 903). Rearmament, economic growth, scientific education-all these were means of internal compensation for international shifts in the balance. The U.S. and the U.S.S.R. confronted each other over each proximate issue, but few of the issues were of decisive importance.

Not only is bipolarity desirable -its proponents claim that it will continue indefinitely; it is a condition to which we must adjust. Patterns of economic growth indicate that the Soviet Union and the
United States will have economic systems more than twice as large as any conceivable competitor until past the year 2000. Nor has the spread of nuclear weapons appreciably influenced the amount of power middle-ranking states can dispose. Britain's nuclear program, so it is argued, is dependent on the U.S., and while France may gain an independent capability, she is likely to find it vulnerable or useless in a crisis. If independent capabilities began to be significant militarily, the nuclear giants would merely increase their offensive or defensive postures (Waltz, I964, pp. 894-95). As a result of modest exertions, the bipolar world would be restored.

\section{Bipolarity: A Critique}

There are, in rejoinder, three arguments against bipolarity as a desirable (or even as the best attainable) international system. The first is that bipolarity comprehends only one of the impulsions to expansion or aggression. While it may be true that international polarization helps to prevent successful expansion by either side, since it calls forth counterpressure by the opposing camp, it does not reduce motivations for expansion and may even increase them. Since the competition between poles is both intensive and extensive, each action by one will be viewed as a strategic gambit by the other. Even actions which may not be intended to have international reference will be seen in terms of the bipolar competition. This in turn must accentuate the political hostility between camps. The antagonism generated on one side by action of the other will be reciprocated, and the tempo of discord will increase. Since the competition is akin to that of a zero-sum game (see Waltz, 1964, p. 882), this is a quite natural outcome. Any advance in the position of one must take place at the expense of his adversary; hence the slightest improvement in the position of one must provoke the other to new exertions. The respective concern to advance or maintain one's position is realistic in the framework of a two-power competition. The psychological climate in which such a struggle takes place, moreover, is likely to be one of growing ill-will. At some point in this degenerative process one side may think not only of the risks consequent upon striking his opponent, but also of the risks he may suffer if he decides not to strike. Eventually reciprocal fears of surprise attack may grow to such a point that they 
cannot be endured. Preventive war may be seen to be preferable to war at the opponent's initiative.

A second disadvantage of the case for bipolarity is that two quite different notions of the term appear to be employed. According to one, the Soviet Union and the United States are engaged in a duel for world supremacy or, at minimum, in a struggle to maintain their relative positions. An action by one directly affects the position of the other; all international changes are of vital significance in that they affect the balance between the two. According to the other notion of bipolarity, however, substantial territorial and/or political changes can take place in international relations without impinging on the overarching stability. The U.S. can "gain" or "lose" China without appreciable impact on the balance. If the latter is true, it is because international politics is not analogous to a two-person zero-sum game. The increment (or decrement) to the U.S. is not a simultaneous loss (or gain) to the U.S.S.R. The "gain" is not at the expense of previously Soviet-held territory; the "loss" is not at the expense of previously American-held territory. China is an independent quantity in world politics, not merely a factor in Soviet or Western strength. If this situation prevails, there can be important shifts in the international balance which do not upset the basic relation between the U.S. and the U.S.S.R. That relation, however, is no longer bipolar. All changes are either vital in that they directly affect the bipolar balance, or they are not vital in that they fail to do so. ${ }^{2}$

Thirdly, the prescription "peace by crisis" is a dubious palliative. It seems equivalent to saying that the world's most peaceful place is on the brink of war. Pacific features may be present in one sense, in that nations presumably try harder to avoid war when they are faced with it as an immediate prospect. But if the will to avoid war is greater, the proximity of war is also greater. Cuban and Vietnamese crises may be stabilizing in that they teach techniques of "crisis management," but they are destabilizing in that there is always the possibility that the lessons will not be

I It should be noted that it is not pertinent to argue that the magnitude of bipolar power vis-à-vis Chinese power is so great that a change in Chinese allegiance is insignificant. If Chinese power is very slight compared with both bipolar powers, the balance between poles is narrow enough to make a switch in alliance of great importance.

2 Waltz recognizes but does not assign due weight to this contradiction (see Waltz, 1964, p. 903). learned. When one decides to fight fire with fire, he engages in a policy of calculated risks. At minimum, it is not unambiguously clear that serial crises are the best means to peace.

Bipolarity also seems to have been confused with détente. Under conditions of détente crises may be manageable, and peace may be preserved. But détente is directly contrary to one of the major formulations of bipolarity. Détente presumes that the interests of two parties can be advanced simultaneously. The zero-sum notion of bipolarity requires that the interests of one can be advanced only at the expense of those of the other. And if it is then maintained that the looser notion of bipolarity is to be accepted in consequence, one may rejoin that a loose bipolar system does not involve an absence of peripheries. The two poles may then remain partially indifferent and unaffected by even significant changes in the distribution of international power. Immediate countervailing pressures, then, are not called forth by each change in the status quo. Imbalance may emerge. In the result one must choose between two different international systems: a system in which change can be accommodated without drastic action by the two major camps and in which, as a result, disequilibrium can occur; or a system in which there is a taut balance maintained by vigilant employment of counterpressure and in which the antagonism between camps is likely to be very great. The first may permit détente but is not strictly bipolar; the second offers stringent bipolarity but rules out accommodation. The two notions are not compatible, and the argument for one undermines the contentions urged on behalf of the other.

\section{Multipolarity}

If bipolarity does not pass muster as a "relevant utopia" for international relations, what of multipolarity? Does it have special advantages to offer? Again a dual argument may be given. Multipolarity, it is maintained, not only meets the requirements of a reasonable utopia, but it can be approximated in future international politics. ${ }^{3}$ Aside from the

3 Hedley Bull, for example, sees warrant for the view that in the next ten years "the system of polarization of power will cease to be recognizable; that other states will count for so much in world politics that the two present great powers will find it difficult, even when cooperating, to dominate them" (Bull, r 963, p. 2 I). 
feasibility of multipolarity, however, three basic reasons commend it to our attention as a desirable international system. First, multipolarity affords a greater number of interaction opportunities (Deutsch and Singer, 1964, pp. 392-96). The number of possible dyadic relationships in a multipolar system is very great, and it rises in increasing proportion to the number of states (poles). This plenitude of interacting partners means that there is a greatly reduced danger of mutually reinforcing antagonism between two states. Individual states will have associations with a great variety of others; their cross-cutting loyalties will tend to reduce hostility expressed toward one particular state or against one particular cause. Multipolarity, it is claimed, avoids the major disadvantage of a bipolar international order. Since world politics would not be a zero-sum game, action by one nation would not require an offsetting response by its single opponent. Instead of the mutual reinforcement of hostility expressed in terms of "positive feedback" there may be the dissipation of hostility through "negative feedback" (Deutsch and Singer, I964, p. 393). Multipolarity, then, provides the basis for a stable social system; bipolarity cannot do so. In addition, not only does the need for the expression of augmented hostility fail to appear, but the availability of alternative partners makes possible a response other than direct challenge or military threat. If a state finds itself the object of hostility, it may respond indirectly by firming its connections with other states. This in turn preserves the peaceful atmosphere.

A second argument offered on behalf of multipolarity is that it diminishes the attention paid to other states (Deutsch and Singer, 1964, pp. 396-400); "... as the number of independent actors in the system increases, the share of its attention that any nation can devote to any other must of necessity decrease" (p. 396). Since a nation can only actively attend to a certain maximum number of other states at any given time, a large multipolar international system will mean that a number of national actions will not reach the threshold of international significance. Conflicts may be limited in this manner. "It is perhaps not excessive to assume that the minimal attention ratio for an escalating conflict would have to be $I: 9$, since it does not seem likely that any country could be provoked very far into an escalating conflict with less than io per cent of the foreign policy attention of its government devoted to the matter" (Deutsch and Singer, 1964, p. 399). An eleven-state world (assuming relative equality of power) would, then, avoid serious conflict (p. 398).

Thirdly, it is contended that a multipolar system, in contrast to bipolarity, has a dampening effect upon arms races. If a state, $A$, is allocating half of its military strength against $B$ and half against $C$ and $D$ together, and B begins to rearm, A's countervailing increment is only half of what it would be if $A$ and $B$ were the only powers in the system. The typical bipolar model, involving an escalating arms race between two opposed powers, then fails to predict the outcome. Multipolarity is responsible for limiting the arms competition.

The proponents of multipolarity admit that there are circumstances under which an international system of many equivalent powers could become unstable. In present-day international politics there are powers more reckless than the Soviet Union and the United States. If these powers obtained a nuclear weapons capability they might use it in a disruptive fashion (Deutsch and Singer, I964, p. 404). But "... if the spread of nuclear weapons could be slowed down or controlled, a transition from the bipolar international system of the early I950s to an increasingly multipolar system in the I960s might buy mankind some valuable time to seek some more dependable bases for world order" (p. 406; authors' emphasis). It is also acknowledged that, while multipolarity is most likely in the near future, in the long run there seems to be a tendency for multipolar systems to break down. "If the probability of states' perishing is small, but larger than zero, and the probability of substantial new powers' arising is zero... then the model will predict a diminishing number of effective contenders, leading eventually to a two-power world or to the survival of a single power..." (p. 405). Assuming restraint on the dispersion of nuclear weapons and imminent multipolarity in the immediate future, however, one can look forward to a more peaceful international environment.

\section{Multipolarity: A Critique}

The case of multipolarity offers remedies for certain of the disadvantages of bipolarity mentioned above. There should be no cause under multipolarity for total international concentration on the reciprocally 
reinforcing hostility between two states. Alternative interests, antagonisms, and connections should distract attention from a focused bilateral struggle. If two-power arms races develop, they should be of much less consequence than under bipolarity. At the same time, multipolarity has its unique deficiencies. At least three points may be raised against it.

First, it seems highly probable that a multipolar world order will increase the number of international conflicts, though it may possibly reduce their significance. A bipolar system can have but one antagonism; multipolarity, on the other hand, may have virtually numberless frictions. While the attentions of international actors will be dispersed throughout the system, the variety of national interests expressed will multiply. Inevitably, national interests are a complex amalgam of popular attitudes, tradition, geographic situation, economic and military strength, ideological orientation, and governmental structure. Since in a multipolar order a great number of states will be significant actors in the system, a bewildering range of claims and interests must ensue. As the other writers have contended, conflict is partly a function of the degree of particularity in the international system (see Waltz, 1959). The greater the gamut of demands, the harder it must be to accommodate them. Thus multipolarity, by increasing diversity, must also increase conflicts of interest.

This assessment may be countered by the argument that the results of multipolar conflict will be much less catastrophic for the international system than the potential results of bipolar conflict; that:

$$
P_{\mathrm{bc}} \times R_{\mathrm{bc}}>P_{\mathrm{mc}} \times R_{\mathrm{mc}}
$$

where $P_{\mathrm{bc}}$ and $R_{\mathrm{bc}}$ are the probability and results of bipolar conflict and $P_{\mathrm{mc}}$ and $R_{\mathrm{mc}}$ are similar quantities for multipolar conflict. The expectation of bipolar conflict (probability times results) would be greater than the expectation of multipolar conflict. This reformulation, however, is open to two difficulties. First, it shows that the advantages of the multipolar system depend on the variable magnitudes assumed. If a multipolar order limits the consequences of conflict, it can scarcely diminish their number. If a bipolar system involves a serious conflict between the two poles, it at least reduces or eliminates conflict elsewhere in the system. The choice between systems, then, depends upon the size of the respective quantities in a given case. Second, if nuclear weapons are widely disseminated in a multipolar environment, bipolarity must be seen to be the better alternative. In such circumstances the greater frequency of multipolar conflict would be accompanied by devastating or disastrous results, and the probability-timesresults formula above would suggest that a bipolar system is preferable.

The second major criticism of the case for multipolarity flows directly from these considerations. If a multipolar international order is as harmonious as its proponents claim, even widespread distribution of nuclear weapons should not destabilize the system. As new states enter, the ensuing diminution of national attention should reduce friction. If states really fail to pay attention to their fellows, what differences should diffusion of nuclear weapons make? That the dissemination of weapons is viewed as crucial, however, indicates that multipolar exponents recognize the latent conflict in a multistate system. States are reckless only if they are, or conceive themselves to be, embroiled in conflict. Those features of multipolarity with which we are familiar (in the nationalist, underdeveloped world) are not characterized by lack of interest or attention. They are marked by a highly political awareness of the postures and attitudes of other states. And if some states do not attend to one another, as might be assumed to be the case in the relations of - - sayThailand and Bolivia, this is by no means a general feature of underdeveloped politics. The occasional discontinuities in communication in one part of the system are more than compensated by the range and depth of contacts, both friendly and hostile, which occur in others. Since these contacts link states of very different national interests, they are bound to produce antagonism. And atomic weapons superimposed on antagonism are a recipe for instability.

Thirdly, a multipolar international system, while reducing the significance of any single change of alignment or military posture, inevitably compounds uncertainty. In a bipolar world, an adjustment in relative position of the two poles is important for the entire system. Changes, however, are relatively simple to predict. In a multipower world a single alteration in alliance combination or military prowess may not be decisive for the system as a whole, but its consequences are far more difficult to 
calculate (see Burns, 1957). The number of tentative combinations is astronomic; military dispositions may take myriad forms. Multipolarity, then, raises the difficulty of policy-making. Results may be altogether unforeseen; choice becomes very complex. Since multipolarity raises incalculability, the system finds it more difficult to achieve stable results. War may occur, not through a failure of will, but through a failure of comprehension. ${ }^{4}$

\section{Toward an Alternative System}

The respective disadvantages of bipolarity and multipolarity as monolithic images of future international systems should not blind us to their attractive features. Bipolarity provides for well-nigh automatic equilibration of the international balance; in addition, while reinforcing conflict between the two poles, it at least has the merit of preventing conflict elsewhere in the system. Multipolarity reduces the significance of major-power conflict by spreading antagonism uniformly through the system. What we should wish for a future relevant utopia is to combine the desirable facets of each without their attendant disabilities. In practice, even the adherents of one or the other find merit in a wider view. The devotees of bipolarity seem implicitly to include the détente (which was a response of the United States and the Soviet Union to their position in a larger international system); the proponents of multipolarity draw back when it is proposed that nuclear weapons be part of the multipolar diffusion of power.

The objective can be accurately described, though it is difficult to give it an appropriate name. The relations between two major powers would be strongly conditioned by the presence and activity of other states. This means that international politics would not be a zero-sum competition between two superpowers. The resources of the international system would not be entirely divided up between the two major states with future outcomes dependent upon a bilateral competition between them. Rather, resources would remain to be appropriated, and the rivalry between the two major protagonists would occur in the external international environment as well as in the national preserves of each. Because

4 It is possible that the origins of World War I owe something to the inability to calculate policies of other states until it was too late to change them. external avenues of possible expansion would exist, neither major state need presume that only a direct conflict with its antagonist could decide the issue. The bilateral conflict might be adjusted or equilibrated through actions in the external realm; gains by one power could be made up by countervailing gains by the other. Nor should serial appropriation decide the ultimate fate of the external international world. If the two great powers merely proceeded to apportion slices of the remaining international pie, they would in time be brought back to a strict bipolar confrontation, with all the horrendous consequences which this might involve. The multipolar features of the external sphere should prevent substantial transfers of real estate and political allegiance. Neither hegemony would be acceptable to burgeoning power centers of the external area; changes of alignment or international disposition would not barter the fundamental independence of external states. The bipolar powers would continue to seek advantages in the multipolar realm, but they would fail to eliminate multipolar orientations.

This failure, in turn, might lead to disenchantment with equilibration via the external realm. The bipolar powers might then seek direct advantages in an intensified struggle over the national position of each. If the multipolar challenge were sufficiently great, however, the bipolar states might reduce their own competition for the purpose of making occasional common cause in opposition to external claims. Ultimately, the bipolar states might seek a détente based on mutual recognition of two rigidities: (I) the difficulty of achieving preponderance in direct internal competition; (2) the difficulty of making major gains in the external environment. Confronting external challenge, moreover, both might realize that the international status quo was preferable to possible foreshadowed deterioration. Since cooperation in international relations tends to be reinforced by conflict elsewhere in the system, resurgence of the multipolar region would produce a tendency toward bipolar agreement.

One of the uncertainties in such a situation would stem from reversals for either of the two major states in the multipolar realm. In order to recoup a lost position of strength, the bipolar states might be tempted to heighten the conflict between themselves to reinsure for a multipolar client the value of past association or alignment. And at present 
the United States has sought to reaffirm nuclear solidarity with its NATO allies by proposing a counterforce strategy directed against the Soviet Union. If the commitment to Europe is underscored in the one case, the détente with Russia is also affected. The multilateral nuclear force, designed to reassure several West European states, also generated Soviet opposition. On the other hand, Soviet attempts to reassure China and North Vietnam of the benefits of the Russian alliance are bound to impinge on U.S. relations. Closer ties with China would inevitably weaken new-found bases of Western accord. In the short run, then, it seems likely that the U.S. will have to accept some erosion of its past position in Europe, while the Soviets will have to adjust to a diminished role in both Eastern Europe and the Far East. If they fail to do so, it will be at the expense of cordiality at the bipolar level.

The maintenance of the détente is of fundamental international significance, both theoretical and practical. It is theoretically important because it avoids the antagonism of the zero-sum game in strict bipolar terms. It also obviates a general trend toward multipolarity, with the loss of control and increase in the frequency of conflict that this would involve. A modicum of bipolar cooperation dampens hostility in the external sphere; interventions may be at least partially designed for the purpose of preventing multipolar conflict that could threaten central bipolar stability. In practical terms the detente is the means by which the spread of nuclear weapons may be channelled, controlled, or halted. It should be observed that nuclear weapons do not affect the theoretical questions of conflict and cooperation. A measure of bipolar agreement has been achieved despite opposing nuclear weapons systems. The dispersion of weapons is important not because of the new conflicts which it creates, but because it sanctions radical options in the waging of old conflicts. In so doing it threatens the balance attained at the bipolar level. Nuclear weapons may also, over a considerable period of time, give the appearance of transforming a bipolar-multipolar order into a system of general multipolarity. This fundamental alteration would be unlikely to occur in fact, but it is one of a range of possible future outcomes.

If the détente is desirable, it is possible to have too much of a good thing. A total bipolar rapprochement, an end to the Cold War, would be likely to create a new bilateral tension between major power and multipower spheres. In practical terms it would represent a conflict of rich countries and poor countries, industrial states and agricultural states, European and colored races, northern and southern nations. This emergent bipolarity would demand a rapid spread of nuclear weapons in previously multipolar areas. It would require a hasty amalgamation of economic systems and pooling of industrial resources: the multipolar area would transform itself through a new political coordination. The zero-sum game might be played once again.

A bipolar-multipolar system, on the other hand, would seek to avoid the extremes of either parent form. Enough bipolar control of multipolar realms would take place to prevent extremes of conflict, or, if conflict could be averted, to dissociate bipolar interests from outcomes in the area. At the same time bipolar competition would continue in multipolar as well as bipolar regions. The two major states would act as regulators for conflict in the external areas; but multipolar states would act as mediators and buffers for conflict between the bipolar powers. In neither case would conflict be eliminated, but it might be held in check. Indeed, if hostilities were suddenly eliminated in one realm but not the other, the result would be adverse to general stability. If conflict cannot be eradicated both generally and simultaneously, its abolition in one part is deleterious to the whole.

\section{Bi-multipolarity}

It is now possible to list the characteristics of an intermediate international system, a system of bi-multipolarity.

\section{Relationship of Interests}

The significant feature of interests in such a system is that they would be partially opposed and partially harmonious. The relation between the bipolar nations would be cooperative in that it would reflect mutual interests in restraining conflict or challenge in the multipolar region. The relation between bipolar powers would be competitive in that each would seek to prevent the other from attaining predominance either militarily or in connections with the multipolar world. The multipolar states would have an equally ambivalent pattern of interests. In regard to one another there would be rivalries stemming from the 
variety of national perspectives and positions; there would also, however, be common interests in resisting the ambitions of the bipolar powers. In regard to the bipolar states there might be individual interests supporting military guarantees or economic assistance from one (or both) of the major powers. There would also be resistance to big-power encroachment. In no case, however, would the pattern of interests resemble that of a zero- or constant-sum game. Bipolar powers would not directly confront one another; multipolar powers would not develop irrevocable antagonisms among themselves; and the multipolar and bipolar worlds would not be completely opposed. Conflict within each sphere and between spheres would be restrained.

\section{Equilibration}

Equilibration, or the redressing of the international balance, will be a more difficult task in a bipolar-multipolar structure than in a strictly bipolar world. Since in the latter system interests are so clearly opposed, any advantage accruing to one evidently must be made up by the other. In a bi-multipolar system where interests are cooperative as well as conflictual, the consequences of a change in the position of one state will be harder to estimate. Since relationships will be more harmonious, on the other hand, the need for equilibration will be significantly reduced.

\section{Predictability}

Policy-making in a bi-multipolar system will be more difficult than in a system of bipolarity. A far greater range of separate national decisions must be considered. At the same time, since the bipolar states will exert an important influence on the trend of events in the multipolar fraction of the world, statesmen would not be confronted by the sheer indeterminacy of a strictly multipolar order. While shifts would be harder to predict than under general bipolarity, the momentousness of each shift would be appreciably less.

\section{Probability of Overt Conflict}

The probability of war, whether local or general, would be much smaller than in a multipolar system. Conflict would be mitigated on two scores: a multipolar buffer might help prevent the two nuclear giants from coming to blows; and the

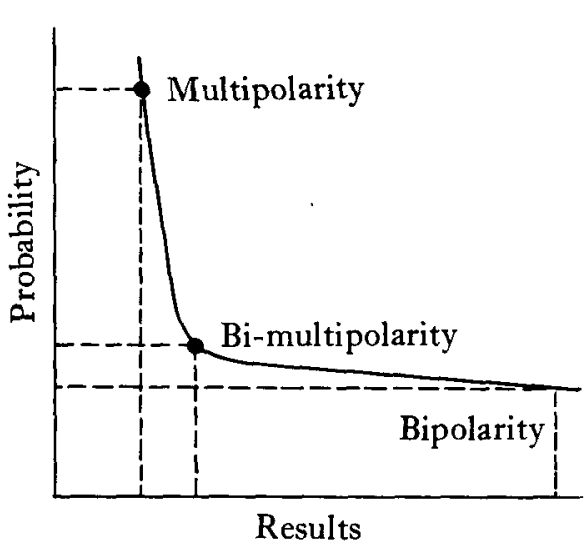

Figure 1. Probability and results of overt conflict in the three different international systems.

restraining influence of the bipolar states might in turn prevent extreme conflict among multipolar powers. While simple bipolarity would not exist, the influence of two superpowers would be crucial in limiting the outcomes of the system.

\section{Results of Overt Conflict}

The results of war, whether local or general, would be much more tolerable than in a bipolar system. Overt conflict would most generally take the form of wars among multipolar states, and while crises between bipolar states might not be ruled out, these would be tempered by recognition of significant mutual interests. As long as the détente continued, there would be few dangers of major nuclear war.

The probability and results of overt conflict in the three different international systems would be roughly as shown in Fig. I. The area of the dotted rectangle under the system-point in each instance indicates the amount of violence sustained by the international system. Bi-multipolarity does not eradicate violence, but it holds the prospect of limiting violence to far smaller proportions than does either bipolarity or multipolarity. If peace is the objective, a system combining bipolar and multipolar features may be a means of a reasonable approximation thereto.

\section{Diffusion of Nuclear Weapons}

The situation depicted would change considerably if nuclear weapons began to be diffused among 


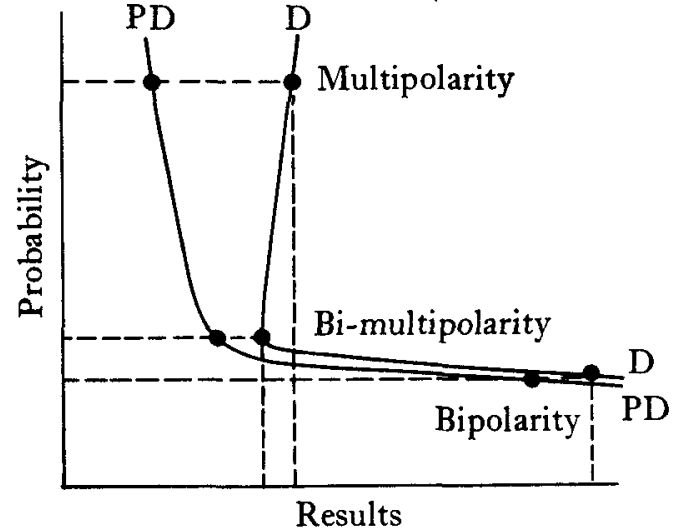

Figure 2. Probability and results of overt conflict before (line PD) and after (line D) nuclear weapons have become available to a large number of states.

quite a number of states. The impact would be greatest on a strictly multipolar system, for the incentives to acquisition would be substantial, and the disincentives involved in having to keep up with nuclear superpowers would be absent. Restraints on acquisition by the larger powers also would be lacking. In a bipolar world nuclear weapons would add least to the dangers already confronted. A cataclysm between two halves of the world would be dangerous enough, even without nuclear bombs, though they would clearly enhance the war's destructive power. In an intermediate international environment, the process of nuclear diffusion would also raise levels of violence, but bipolar influence within the system would either reduce the scope of diffusion or limit its disruptive impact.

The results would be roughly as shown in Fig. 2. If $P D$ charts the results of international conflict in a prediffusion era, line $\mathrm{D}$ describes the outcomes after nuclear weapons have become available options for a large number of states. While bipolarity remains unattractive because of the dire consequences of conflict between the two protagonists, multipolarity has lost most of its previous advantages. Now the probability of conflict not only remains high, but the disastrous results of that conflict are clearly portrayed. Relative to the extremes of bipolarity on the one hand and multipolarity on the other, the intermediate system retains great appeal.

\section{Bi-multipolarity and the Present International Scene}

The system of bi-multipolarity should not be confused with the present international order. One of the major characteristics of the contemporary international scene resides in the difference in attitude and position of the allies of the great powers and neutral states. Two factors seem to account for this. On the one hand, nonaligned nations have received

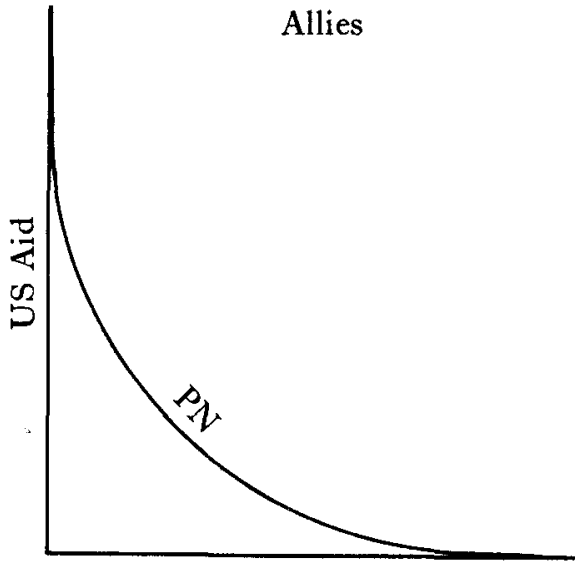

USSR Aid

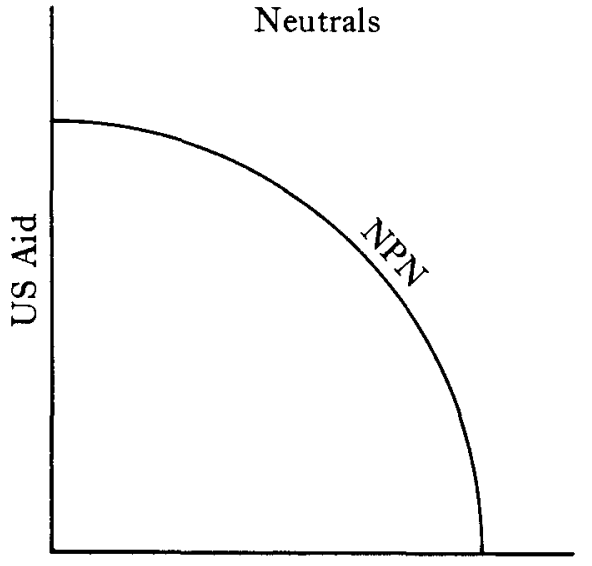

USSR Aid

Figure 3. Differential treatment received by allies and neutrals in terms of economic aid from the U.S. and the U.S.S.R. PN is a "penalize neutralism" curve, while NPN is a "not penalize neutralism" curve. 

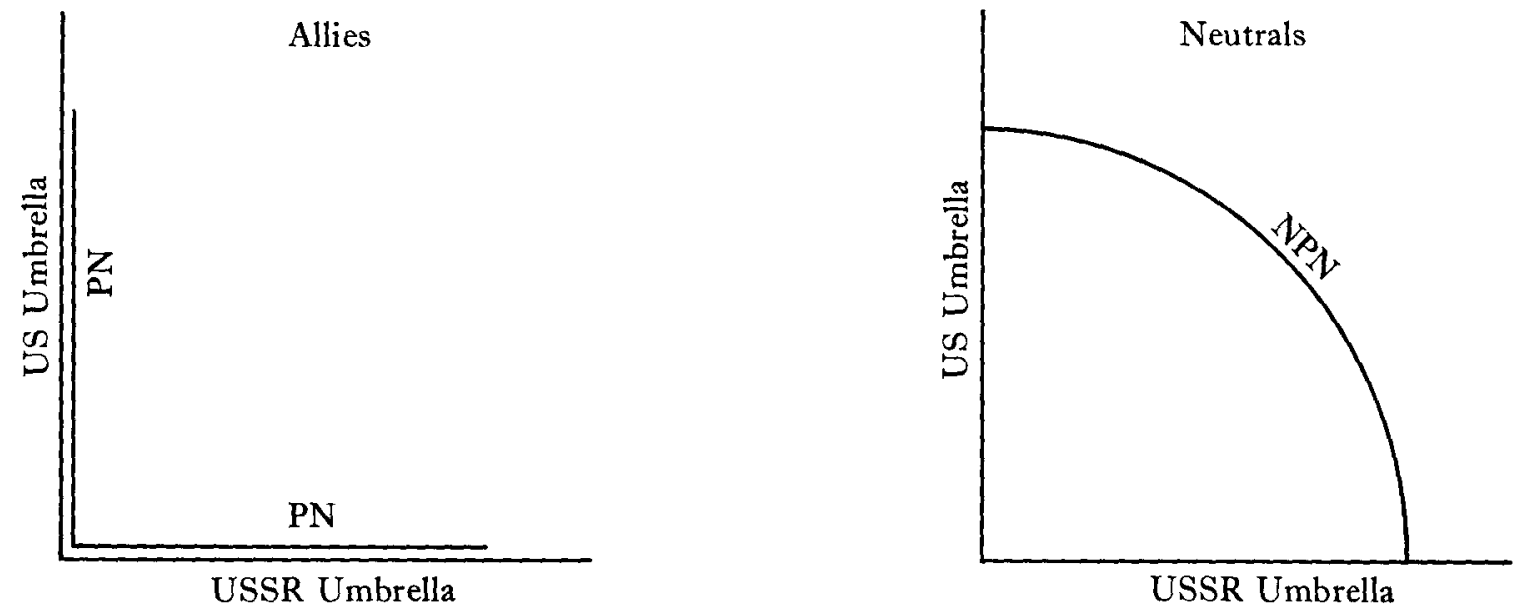

Figure 4. Differential treatment received by allies and neutrals in the nuclear "umbrella" guarantees of the U.S. and the U.S.S.R. As in Fig. 3, PN and NPN indicate policies of penalizing and not penalizing neutralism.

certain of the benefits of alliance protection and assistance without pledging political allegiance to either bipolar camp. This continuing phenomenon has occasioned some disaffection among the formal allies of the two major powers. It has, in a measure, devalued the currency of alliance. On the other hand, the partial attempts at détente have made alliances seem less necessary. If a continuing Cold War were not the order of the day, former client powers would have less reason to guard, via great poweralliances, against a sudden unfavorable change.
At the moment we seem to be in a phase in which the two major powers are placing enhanced emphasis on their formal alliances. The Soviet Union has come back into Far Eastern international relations, apparently striving to improve its ties with China and to reassert its influence in North Vietnam. Until recently, at least, the United States seemed engaged in an effort to reestablish a strong position within NATO. In both cases it remains unclear whether maintenance of a strong alliance position or an enduring atmosphere of détente and/or peaceful

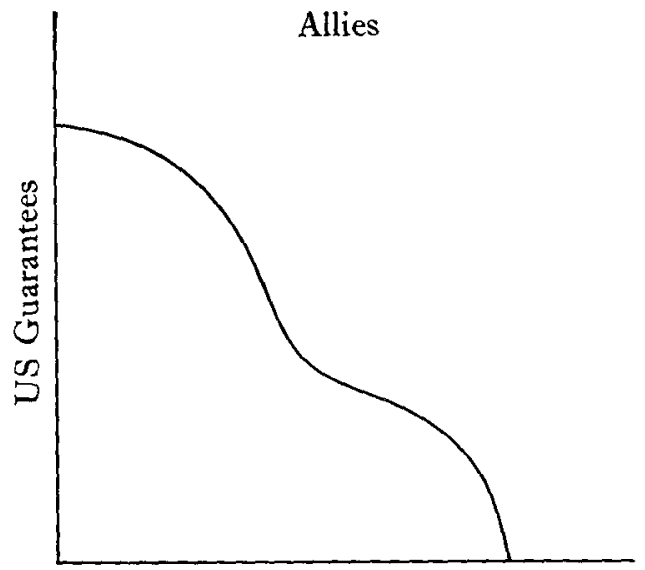

USSR Guarantees

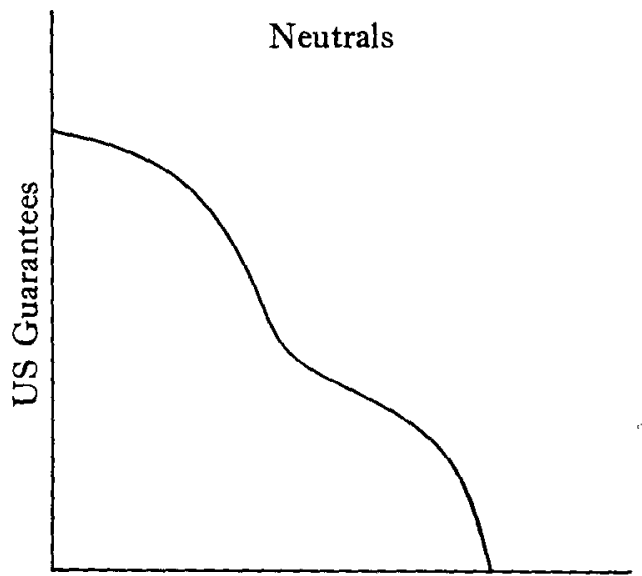

USSR Guarantees

Figure 5. A possible final equilibrium position for allies and neutrals with respect to economic and military guarantees from the U.S, and the U.S.S.R. 
coexistence is most important. The issue is a complicated one in practice because any disengagement of interests, justified on grounds of relaxation of tension, may be interpreted by a bipolar opponent as a sign of weakness and a signal for adventure.

In the longer run, however, there are potentialities for the bipolar-multipolar world we have been discussing. It will probably involve treating nonaligned states somewhat less favorably and aligned nations somewhat more favorably than has been the case up to the present. It seems uncertain, however, that the two aligned camps will continue as presently organized into the indefinite future. The reasons for this uncertainty can be seen in Fig. $3 .{ }^{5}$ The two diagrams show the differential treatment that allies and neutrals have received in the aid-giving behavior of the United States and the Soviet Union. Among neutrals, roughly speaking, the NPN (not penalize neutralism) curve has been followed, permitting a recipient country to receive sizable quantities of assistance from the opposing bipolar power. Among allies, on the other hand, the PN (penalize neutralism) curve has been followed, providing for substantial reductions of assistance as the ally in question gains additional aid from the opposing camp. If allies suffered in comparison to neutrals in terms of economic and other assistance, they had the compensation of participating in deterrence alliance systems, the protection of which was presumably denied to neutralist nations. As a result of the threatened spread of nuclear weapons today, however, it is no longer certain that allies alone may enjoy the benefits of deterrent protection. India, in particular, may be able to retain her nonalignment

5 I am indebted to Professor Albert O. Hirschman of Columbia University for the basic notions of the figures which follow (Hirschman, r 964). while participating in nuclear guarantees of the big powers. If this occurs generally in the neutralist world, an equivalent disproportion in the treatment of allies and neutrals might come to exist in the military sphere, as shown in Fig. 4. Such outcomes would so disadvantage allies and reward neutrals that a considerable movement toward greater neutrality would have to be expected. A final equilibrium might be attained, covering both economic and military guarantees in roughly the form shown in Fig. 5 .

In such a case, of course, there would no longer be a difference between allies and neutrals. The growth of multipolar sentiment would presumably reinforce the détente between bipolar powers, and an important step in the direction of an intermediate international system would have been taken.

\section{References}

Bull, Hedley. "Atlantic Military Problems: A Preliminary Essay," prepared for the Council on Foreign Relations meeting of November 20, 1963 , p. 21 .

Burns, Arthur. "From Balance to Deterrence: A Theoretical Analysis," World Politics, X, 4 (July 1957).

Deutsch, Karl, and Singer, J. David. "Multipolar Power Systems and International Stability," World Politics, XVI, 3 (April 1964), 390-406.

Hirschman, A. O. "The Stability of Neutralism: A Geometric Note," American Economic Reviev, LIV (1964), 94-100.

Hoffmann, Stanley. "International RelationsThe Long Road to Theory," World Politics, XIII, 3 (April $196 r$ ).

Waltz, Kenneth N. "The Stability of a Bipolar World," Daedalus (Summer 1964). Man, the State, and War. New York:
Columbia, 1959. 